\title{
Isis and antisense face crucial test without Novartis
}

In November, Isis Pharmaceuticals (Carlsbad, CA) announced the departure of its longstanding partner, Novartis Pharmaceuticals (Basel, Switzerland), leaving the small biotech company to underwrite development of two antisense compounds, Isis 3521 and Isis 5132. Isis also announced a significant new financing arrangement and positive results from phase II trials of the two compounds. The outcome of these developments is expected to impact the entire field of antisense technology.

Although other companies, including Novopharm Biotech (Winnipeg, Manitoba, Canada), Hybridon (Milford, MA), and Sequitur (Natick, MA), are working on antisense, Isis owns key patents in the field and is the only company with compounds in clinical trials, according to Sushant Kumar, analyst at Mehta Partners (New York).

News of Novartis's departure coincided with the release of phase II trial results of Isis 3521 and Isis 5132: Isis 3521 showed significant efficacy against lung cancer in a group of 15 patients who also received standard chemotherapy, and results from the Isis 5132 cancer treatment trial were also positive, but less impressive. Novartis's decision to leave Isis, therefore, suggests that the two companies have differing corporate priorities. "We have some criteria of results we need to go ahead," says Felix Raeber, Novartis spokesperson, adding that "with these two substances, [the data were] not what we expected."

Raeber refused to elaborate, except to state that Novartis originally pursued the partnership with Isis primarily to develop antisense technology that could be used in more basic functional genomics research, rather than direct therapeutic applications. Stanley Crooke, Isis CEO, suggests that the size of the market for Isis 3521, which would be used in combination with other companies' chemotherapy agents, might be "less than what Novartis is interested in ... the drug by definition is vastly more important to us [than to Novartis]."

Under the original agreement, Novartis covered the costs of clinical trials for the Isis compounds in exchange for ownership of the drugs. With Novartis gone, Isis owns the compounds, but will have to finance phase III trials itself or find a new partner. Novartis spent approximately $\$ 45$ million on the development of Isis 3521 and Isis 5132 and also purchased \$18 million in Isis stock during the development program.

Fortunately, a new financing arrangement - with an unnamed investor that Crooke identifies as "an institution that we've had an

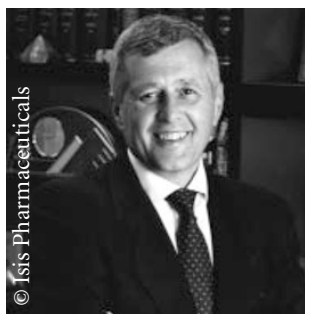

Isis CEO Stanley Crooke. With Novartis gone, Isis will have to finance phase III trials itself or find a new partner.

ongoing relationship with already-an extremely large bank"-will provide substantial backing for the upcoming phase III trials. Under this deal, finalized in November, Isis can sell up to $\$ 120$ million worth of stock-equal to about $26 \%$ of the company's current market capitalization - to the bank when it needs cash. "I think for Isis it's a great deal-[Isis] needed to do at least one round of financing of this sort before being able to see revenues from their lead product," says Mehta Partners' Kumar.

Isis is also considering pursuing marketing partnerships for its compounds currently in clinical trials, and Crooke claims that the new financing arrangement "strengthens our resolve to try to retain our rights more, and it also strengthens our hand in negotiations with interested parties."

Isis already has one antisense drug, Vitravene, on the market, but that compound is owned and marketed in the US, Europe, and Brazil by Novartis's Ciba Vision arm under a royalty agreement with Isis. Vitravene, a topical treatment for cytomegalovirus (CMV) retinitis in AIDS patients, also occupies a shrinking market niche, as new AIDS treatments are decreasing the prevalence of CMV retinitis.

Alan Dove

As Nature Biotechnology went to press, Isis announced that the initial analysis of data from a pivotal trial of Isis 2302 for the treatment of Crohn's disease was disappointing. Despite positive interim results for the first 150 patients in the study, the full, 300patient trial failed to show significant efficacy when compared to placebo. Crooke said he was "highly perplexed" at the "anomalous behavior" of the trial and acknowledged that it was a significant setback for Isis just as it was at the point of realizing the potential of antisense technology. Indeed, Isis stock price plummeted nearly $64 \%$ to $\$ 5.59$ on the day of the announcement, and Isis said it anticipated "significant restructuring." However, Crooke remained optimistic about antisense. "From a technology standpoint, this means very little," he insisted. Isis 2302 is the first systemically administered antisense therapeutic compound. Full analysis of the results is expected in the next few weeks. 